\title{
Celebration of the centenary of a major scientific milestone thanks to Heinrich Barkhausen
}

\author{
Patrice Salzenstein ${ }^{*}$ and Ekaterina Pavlyuchenko ${ }^{* *}$ \\ Centre National de la Recherche Scientifique (CNRS), Franche Comté Electronique Mécanique Thermique Optique Sciences et \\ Technologies (FEMTO-ST) Institute, Université de Bourgogne-Franche-Comté (UBFC), 15B avenue des Montboucons, Besançon \\ 25030, France
}

Received: 21 September 2020 / Accepted: 1 November 2020

\begin{abstract}
Brief history of a perfect optimization with the oscillation condition and microwave tube as well as contributions to oscillators at the occasion of the centenary of a great step forward thanks to genius Heinrich Barkhausen with his pages of glory in the years 1919-1920.
\end{abstract}

Keywords: Barkhausen criterions / Barkhausen-Kurz oscillator / microwave tube / electrical engineering / oscillator / optimization

\section{Introduction}

As the year 2020 is well underway, it is useful to remember that the time is not so far away, when we didn't understand physical phenomena. This is the case, particularly in the field of electronics. Such progress has been made in such a short time. We live surrounded by connected objects and microelectronics, everywhere in our everyday devices. But we do not necessarily think every day that great Scientists have made possible these advances. Each step, each progress is the fruit of the long chain of scientists. He is a man to be remembered this year in particular, because a hundred years ago he made the greatest advances which have made it possible to understand the initiation of the phenomenon of oscillation. This man, this great scientist, is Heinrich Barkhausen. When we talk about optimization, we cannot, not mention him.

This article therefore addresses the centenary of his decisive contributions to the understanding of oscillation phenomena, but also the existence of ferromagnetic domains. This will be the subject of a part which will be devoted to Heinrich Bakhausen's main contributions to oscillators.

After a few words to insist on the necessary recognition that we owe him, and an encouragement to quote his essential works, it is also necessary to remember a darker side of this man with his attitude, to say the least, passivity during nazism. But we will retain as a priority that this

\footnotetext{
* e-mail: patrice.salzenstein@femto-st.fr

** Formerly in the laboratory.
}

Genius of electrical engineering has contributed to major advances in modern science. It will then be time to conclude this article dedicated to Heinrich Barhausen's major contributions.

\section{Heinrich Barkhausen's main contributions to oscillators}

The article inevitably addresses the Bakhausen criterion since it is a question of starting the oscillation condition [1]. Every researcher and engineer who works on oscillators knows that it is essential to meet the Barkhausen criteria before being able to start an oscillator. An example is given through these references corresponding to work on crystal oscillators and other types of optoelectronic oscillators [2-6]. This does not guarantee that the oscillator will be stable and that the oscillation will continue, but it is an essential part. It is in fact necessary that the gain of the amplifier compensates for the losses, in particular those which are due to the attenuation through the resonant element. There is also a condition on the phase. This is of course possible due to the understanding of physical phenomena in electrical engineering thanks to this illustrious scientist whom we are talking about in this article.

Before going further, it is nice to remind of a little history of the electronics of the oscillators. So lets write directly about the illustrious scientist Heinrich Georg Barkhausen. He was born 2 December 1881 in Bremen and died 20 February 1956 in Dresden, Germany. He got is PhD in 1907 at the university of Göttingen. Between 1907 and 
1911, he worked in Berlin at the Siemens and Halske laboratories. In 1911, he became Professor of electrical engineering specializing in telecommunications at the Technical Academy of Dresden in the Land of Saxony. It has to be underlined that it was the first time in the world a position of professor was created for him in this year 1911 in the field of electrical engineering. He worked on spontaneous oscillation. He also proposed methods for measure of loudness in the acoustic domain. His most important discovery which made his name to posterity dates from 1919. He then discovered an effect well known now as the the Barkhausen effect. He shows that magnetization results more from a magnetic organization

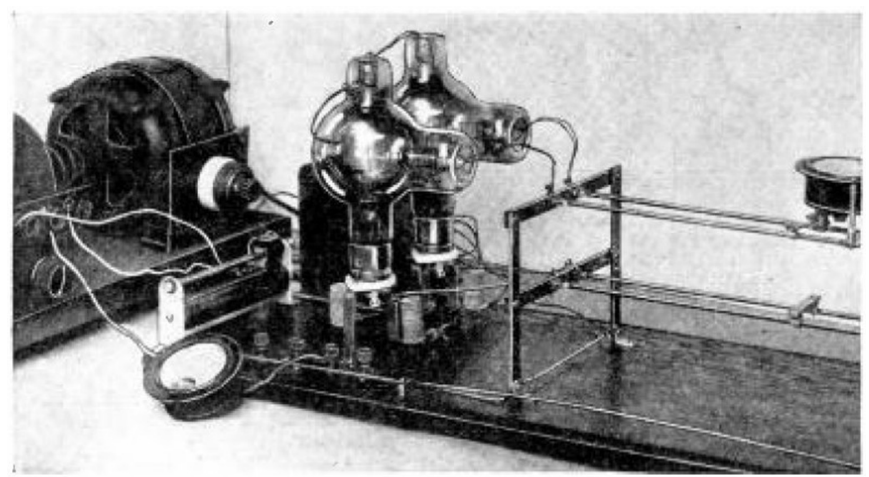

Fig. 1. An experimental push-pull Barkhausen oscillator in 1933, which uses Lecher lines (quarter-wave parallel wire transmission line stubs) as the tank circuit. It could generate 5 watts at $400 \mathrm{MHz}$. Picture in the public domain (The Short Wave Craft magazine's copyright was not renewed after 1962 and it is in the public domain.). of matter, rather than from an action of individual atoms alone. It obviously highlights existence of ferromagnetic domains, which had already been envisaged by theory. Barkhausen is at the origin of the discovery that a slow and progressive increase in a magnetic field applied to a ferromagnetic material causes a magnetization not continuous but by jumps which can be detected by a winding of wire wound on the ferromagnetic material. These jumps are interpreted as discrete changes in the size or rotation of the Christian Samuel Weiss zones, well known mineralogist from Leipzig, Germany. In 1920, Heinrich Barkhausen developed with his colleague Karl Kurz a high frequency oscillator, the Barkhausen-Kurz oscillator or tube B-K, which is considered to be a precursor of the microwave tube [7]. It was for ultrahigh frequencies at $1.7 \mathrm{GHz}$. It explained the the principle of velocity modulation. Barkhausen-Kurz oscillator led to the understanding of the principle of velocity modulation. This Barkhausen-Kurz oscillator is given on Figure 1 [8]. Thanks to it, the first experimental microwave relay system, a $1.7 \mathrm{GHz}$ link 40 miles across the English channel in 1931 between Dover, UK and Calais, France, used a Barkhausen-Kurz tube mounted at the focus of the 10 foot dish. The 10 foot $(3 \mathrm{~m})$ diameter dishes transmitted voice, telegraphy, and facsimile images over 1.7 GHz. It had a radiated power of about 0.5 watt [9]. Two Barkhausen-Kurz tubes were used at the focus of the transmitter and receiver parabolic antennas.

A magazine explained how works the Barkhausen-Kurz tubes in 1938 [10]. Figure 2 illustrates how BarkhausenKurz tubes work.

Heinrich Barkhausen listed the stability conditions for this type of component, the Barkhausen stability criterion, which establishes that an oscillator oscillates if the total phase shift between the input of the component and the output, and the return to the component input is a whole
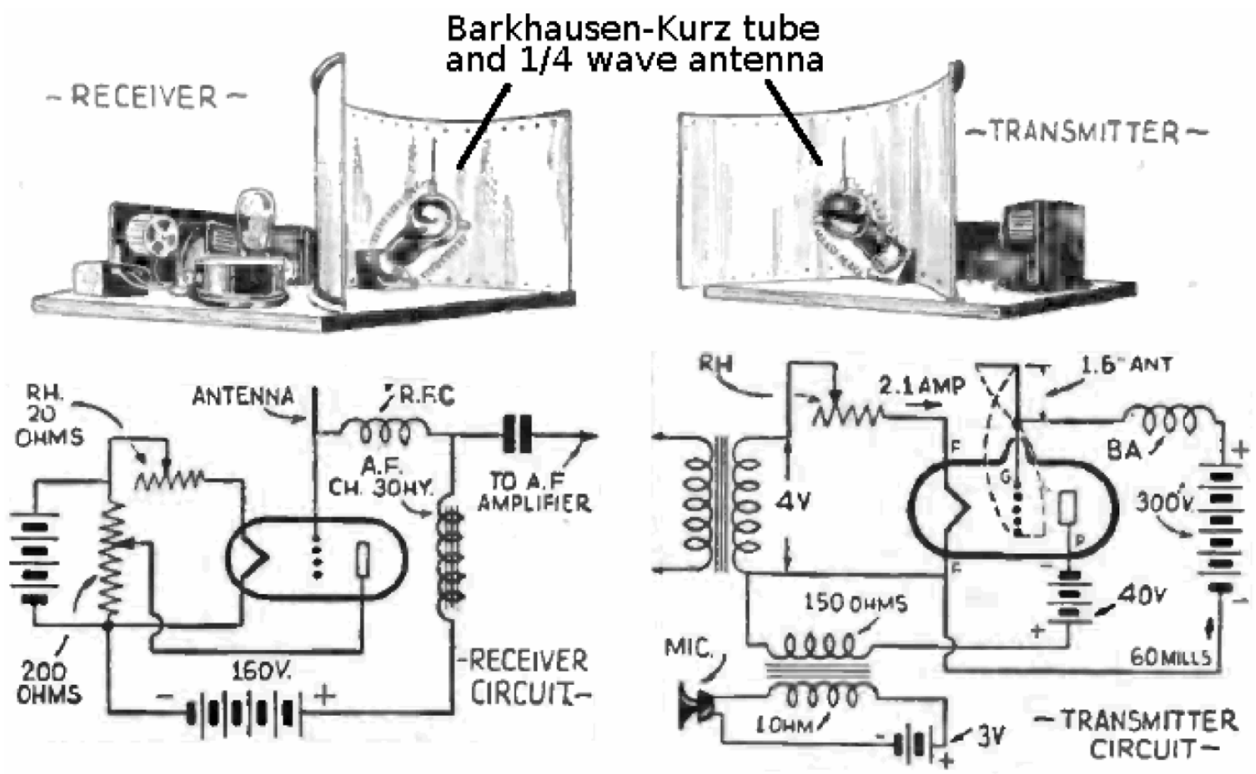

Fig. 2. Experimental low power $3 \mathrm{GHz}$ AM communication link from 1938 uses Barkhausen-Kurz tubes for both transmitting and receiving. The transmitting or receiving antenna is each time placed at the focus of the parabolic mirrors. Electrical diagrams of the transmitter and the receiver are shown in this figure. Picture in the public domain (Short-Wave and Television magazine's copyright was not renewed after 1978 and it is in the public domain.). 


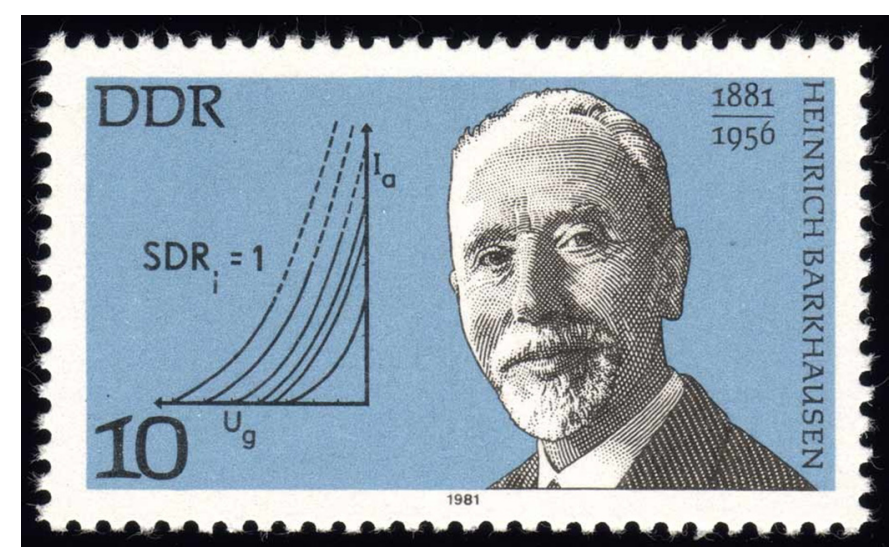

Fig. 3. Stamp with the effigy of Heinrich Barkhausen, which celebrates the centenary of his birth and his contribution to science, in 1981 in the German Democratic Republic (This stamp is in the public domain in Germany because it was released by the postal administration of the German Democratic Republic whose legal successor is the Federal Republic of Germany.).

number multiple of $360^{\circ}$ and if the component gain is 1 . The Barkhausen stability criterion sets a necessary condition for a circuit consisting of an amplifier and a feedback loop to spontaneously start to oscillate. This criterion does not however make it possible to affirm that the oscillations will be durable, nor that they will be of constant amplitude. This criterion marks the beginnings of the study of oscillating circuits. We celebrate this year the genius of Heinrich Barkhausen. So, it is not possible to imagine not to write such article about him whose centenary is celebrated this year. It includes Heinrich Barkhausen and his colleague Karl Kurz, and of course also to his reference book which report about this Barhausen criterions established in 1920 and which was published in 1931 [11], and republished many times in the years which followed, being regarded as the reference book in the field and used by generations of students in Germany and around the world. It is also quite remarkable to point out that the article by Zeitschrift für Physik is part of the first volume of this German physics journal which was created in 1920 in Heidelberg and which existed until its merger in 1997 with the European Physical Journal. With Heinrich Barkhausen, great pages of German and international physics were written, and it is unthinkable that the authors do not quote Heinrich Barkhausen, so much is it necessary to celebrate and cite him. That's why it is obvious to cordially invite future authors working on oscillation criteria to cite these two fundamental papers on the criterion of Heinrich Barkhausen.

\section{The great scientist, the recognition he received and a controversy}

Regarding a photography of Heinrich Barkhausen, it is appropriate to show this stamp published in 1981 in the German Democratic Republic (GDR) on the occasion of the centenary of his birth in 1881. It is shown on Figure 3.
It shows that the GDR preferred to retain the benefit that this renowned scientist brought to science. It is important to point this out. Indeed, the GDR regime is not known to have paid tribute to personalities who were close to Nazism. And as we will see in the next part, a controversy exists because of his attitude after the Nazis came to power in Germany.

Heinrich Barkhausen was a member of the German Academy of Sciences in Berlin and of the Saxonian Academy of Sciences. He was awarded from the IEEE Morris N. Liebmann Memorial Award prize in 1933 by the Institute of Radio Engineers. One of his achievement was to have created the Institute of High-Frequency and Electron-Tube Technology in Dresden. After the second world war, this institute was destroyed during the massive bomb strikes on Dreseden. He helped to build again this institute after the war, just before to be kindly encouraged to end his carrier, due to his attitude in the years 1933 .

Many German scientists had to flee [12] because of purges of Jewish and antinazis professors after April 1933 in German Universities. Unfortunaltly, as many other scientists, Heinrich Barkhausen signed in November 1933, the "Vow of allegiance of the Professors of the German Universities and High-Schools to Adolf Hitler and the National Socialistic State" in support of the Third Reich. The role and attitude of German universities towards Nazism is not very glorious [13]. Although Heinrich Barkhausen was a brilliant inventor of electronics, it is sad he signed this act of allegiance to Nazism. After the bombings of Dresden and the fall of the Reich in 1945, he was put on leave from his academic career and ended his life with the relative indifference of the scientific community until his death in 1956 in Dresden.

It is necessary to cite François Rabelais (1494-1553) who wrote that "Science without consciousness is only ruin of the soul" (in French: Science sans conscience n'est que ruine de l'âme). This quote appears in the letter that Gargantua wrote to his son Pantagruel [14], in Chapter 8 of his book masterpiece called "Pantagruel". Science is the sum of knowledge that it is possible to acquire and accumulate. Consciousness is the fact of using this knowledge wisely. It is to measure the impact of what one has learned. It is understanding the teachings to approach divine intent. It is therefore the path of wisdom and knowledge.

About Heinrich Barkhausen, we will only remember his contributions made before the First World War.

\section{An encouragement not to forget to cite his work}

Researchers and especially young researchers sometimes seem to forget that generations of electronic scientists and engineers have worked before them and made their essential contribution to the common "edifice" of electronics. To avoid too much simplistic reference lists in modern publications, it would be nice if they come with a bibliography that could be purified of too recent references, 
but fleshed out with the papers which really deserve to be cited. It is the very principle of science to cite each of the electronics engineers who made it possible to get to where we are now. In electronics for instance, it would seem surreal if we ignore the work of Edwin Henry Colpitts in 1918 on the famous oscillator that bears his name [15], and the work carried out with his colleague Ralph Vinton Hartley at and around this period. Authors cannot propose an article for publication if they don't cite the names of those who invented and discovered the type of oscillators on which we all work and which we seek to improve. This is exactly the case about the main decisive contributions of Heinrich Bakhausen. It is also the justification of this tribute and article to recall his essential contribution.

The work of Heinrich Barkhausen has largely inspired major publications. We can for example cite Barkhausen Effect [16] and Propagation of Large Barkhausen Discontinuities $[17,18]$ and some other studies to go further in details on what concerns Barkhausen criterions and noise [19-21]. Papers also appear regularly to better understand Barhausen's criteria and starting conditions [22-24].

\section{Conclusion}

Heinrich Barkhausen will go down in the history of science as the inescapable pioneer who pioneered the world of oscillators both theoretically and practically. We prefer to remember that Heinrich Barkhausen was a great scientist and forget his passivity during the war. It is important to celebrate his scientific production of the years 1919-1920 on the occasion of this centenary and honor this great scientist who contributed widely to optimization of the understanding of oscillators.

\section{References}

1. L. von Wangenheim, On the Barkhausen and Nyquist stability criteria, Analog. Integr. Circuits Signal Process. 66, 139-141 (2011)

2. P. Salzenstein, An example of design, optimization, stabilization and noise performances of resonator based optoelectronic oscillators, Int. J. Simul. Multidiscip. Des. Optim. 10, A2 (2019)

3. P. Salzenstein, Frequency and temperature control for complex system engineering in optoelectronics and electronics: an overview, Int. J. Simul. Multidiscip. Des. Optim. 11, 7 (2020)

4. P. Salzenstein, A. Kuna, L. Sojdr, J. Chauvin, Significant step in ultra high stability quartz crystal oscillators, Electron. Lett. 46, 1433-1434 (2010)
5. P. Salzenstein, M. Mortier, H. Sérier-Brault, R. Henriet, A. Coillet, Y.K. Chembo, A. Rasoloniaina, Y. Dumeige, P. Féron, Coupling of high quality factor optical resonators, Phys. Scr. T157, 014024 (2013).

6. P. Salzenstein, E. Pavlyuchenko, Determination of the uncertainty for phase noise delivered by an optoelectronic based system, Proc. SPIE 8772, 877217 (2013)

7. H. Barkhausen, K. Kurz, Die kürzesten, mit Vakuumröhren herstellbaren Wellen [The shortest shafts that can be produced with vacuum tubes], Phys. Z. 21, 1-6 (1920)

8. J. Millen, Experimental $3 / 4$ meter transmitters and receivers, Short Wave Craft magazine, Popular Book Corp., New York 3, 648 (1933)

9. E.E. Free, Searchlight radio with the new 7 -inch waves, Radio News magazine, Radio Science Publications, Inc., New York 13, 107 (1931)

10. C.W. Palmer, Transmitting and receiving on $15 \mathrm{~cm}$, ShortWave and Television magazine, Popular Book Corp., New York 8, 476 (1938)

11. H. Barkhausen, Lehrbuch der Elektronen-Röhren und ihrer technischen Anwendungen [Textbook of electron tubes and their technical applications] original edition in German. (1st edition, Editor: S. Hirzel, Leipzig) (1931)

12. A. Grant, The scientific exodus from Nazi Germany, Physics Today 71, (2018). doi: 10.1063/PT.6.4.20180926a

13. D. Detzen, S. Hoffmann, Accountability and ideology: the case of a German University under the Nazi regime, Account. Hist. 103237321983630 (2019)

14. N. Le Cadet, Le monde de l'édition humaniste et la naissance de Pantagruel (ch. XXX), Réforme Humanisme Renaiss. 1, 25-44 (2016)

15. E.H. Colpitts, Oscillation generator, US Patent US1624537 published 1 February 1918 and issued 12 April 1927

16. E.P.T. Tyndall, The Barkhausen effect, Phys. Rev. 24, 439 (1924)

17. K.J. Sixtus, L. Tonks, Propagation of large Barkhausen discontinuities, Phys. Rev. 37, 930 (1931)

18. K.J. Sixtus, L. Tonks, Propagation of large Barkhausen discontinuities II, Phys. Rev. 42, 419 (1932)

19. J.A. Krumhansl, R.T. Beyer, Barkhausen noise and magnetic amplifiers. II. Analysis of the noise, J. Appl. Phys. 20, 582 (1949)

20. R.S. Tebble, I.C. Skidmore, W.D. Corner, The Barkhausen effect, Proc. Phys. Soc. 63, 739 (1950)

21. G. Biorci, D. Pescetti, Frequency spectrum of the Barkhausen noise, J. Appl. Phys. 28, 777 (1957)

22. V. Singh, A note on determination of oscillation startup condition, Analog. Integr. Circuits Signal Process. 48, 251-255 (2006)

23. V. Singh, Discussion on Barkhausen and Nyquist stability criteria, Analog. Integr. Circuits Signal Process. 62, 327-332 (2010)

24. F. He, R. Ribas, C. Lahuec, M. Jézéquel, Discussion on the general oscillation startup condition and the Barkhausen criterion, Analog. Integr. Circuits Signal Process. 59, 215-221 (2009)

Cite this article as: Patrice Salzenstein, Ekaterina Pavlyuchenko, Celebration of the centenary of a major scientific milestone thanks to Heinrich Barkhausen, Int. J. Simul. Multidisci. Des. Optim. 11, 24 (2020) 